\title{
Invasive crayfish reduce food limitation of alien American mink and increase their resilience to control
}

Article

Accepted Version

Melero, Y., Palazón, S. and Lambin, X. (2014) Invasive crayfish reduce food limitation of alien American mink and increase their resilience to control. Oecologia, 174 (2). pp. 427-434. ISSN 0029-8549 doi: https://doi.org/10.1007/s00442013-2774-9 Available at https://centaur.reading.ac.uk/83113/

It is advisable to refer to the publisher's version if you intend to cite from the work. See Guidance on citing.

To link to this article DOI: http://dx.doi.org/10.1007/s00442-013-2774-9

Publisher: Spinger

All outputs in CentAUR are protected by Intellectual Property Rights law, including copyright law. Copyright and IPR is retained by the creators or other copyright holders. Terms and conditions for use of this material are defined in the End User Agreement.

$\underline{\text { www.reading.ac.uk/centaur }}$ 
Central Archive at the University of Reading

Reading's research outputs online 
3 Invasive crayfish subsidize invasive American mink populations and increase their

4 resilience to control

5
Yolanda Melero, Santiago Palazón, Xavier Lambin

Yolanda Melero (corresponding author), Xavier Lambin

School of Biological Sciences, University of Aberdeen, AB24 2TZ Aberdeen, UK

e-mail: y.melero@abdn.ac.uk

telephone: $+44(0) 1224272789$

\section{Santiago Palazon}

Department of Animal Biology (Vertebrates), University of Barcelona, 08028 Barcelona, Spain

Biodiversity and Animal Protection Service, Generalitat de Catalunya, 08017 Barcelona, Spain

\section{Abstract}

Trophic relationships between invasive species in multiply invaded ecosystems may reduce food limitation relative to more pristine ecosystems and increase resilience to control. Here, we consider whether invasive predatory American mink are trophically subsidized by invasive crayfish. We collated data from the literature on density and home range size of mink populations in relation to the prevalence of crayfish in the diet of mink. We then tested the hypothesis that populations of an invasive predator reach higher densities and are more resilient to lethal control when they have access to superabundant non-native-prey, even in the absence of changes in density dependence hence compensatory capacity. We found a strong positive relation between the proportion of crayfish in mink diet and mink population density, and a negative relation between the
Formatted: Spanish (Spain)

Formatted: Spanish (Spain)

Formatted: Spanish (Spain)

Field Code Changed

Formatted: No underline, Font color: Auto, Spanish (Spain)

Formatted: Spanish (Spain)

Formatted: No underline, Font color: Auto, Spanish (Spain)

Formatted: Spanish (Spain) 
proportion of crayfish in mink diet and mink home range size, with crayfish

contribution to mink diet reflecting their abundance in the ecosystem. We then explored the consequence of elevated mink density by simulating a hypothetical eradication program with a constant harvest in a Ricker model. We found that mink populations were more resilient to harvest in the presence of crayfish. As a result, the simulated number of mink harvested to achieve eradication increased by a $500 \%$ in the presence of abundant crayfish if carrying capacity increased by $630 \%$. This led to a threefold increase in time to eradication under a constant harvest and approximately 20 fold increase in the cumulative management cost. Our results add to evidence of interspecific positive interactions involving invasive species and our simple model illustrates how this increases management cost.

Keywords: Trophic subsidy, Positive interactions, Introduced species, Management cost, Invasibility

Author Contributions: YM and XL designed the study. YM performed the literature search and analyses with advice provided by XL and SP, YM and XL wrote the manuscript.

The authors declare no conflict of interest.

\section{Introduction}


Biological invasions are having a major impact on the Earth's biodiversity with invasive non-native species disrupting the composition, organization and function of many ecosystems (Mack et al. 2000; United-Nations 1996; Vitousek et al. 1996; Relyea 2003). It has been suggested that the invasibility of an ecosystem varies according to species diversity and the properties of species interaction networks in recipient ecosystems (Elton 1958; Tilman 1997; Lonsdale 1999; Fridley et al. 2007), with evidence indicating that invasibility decreases with increasing species diversity (Stachowicz et al. 1999; Fargione and Tilman 2005). Nonetheless, there is growing evidence that interactions can also modify the resistance of a community to invasion (Bruno et al. 2003; Bulleri et al. 2008; Rodriguez-Cabal et al. 2012). For example, native species can increase the fitness or population density of invasive species and vice versa. Lenz and Facelli (2003) found that native chenopod shrubs increased the survival of the invasive stem succulent Orbea variegata by reducing temperature and radiation, whereas Tablado et al. (2010) observed how the invasive red swamp crayfish Procambarus clarkii increased the abundance of native vertebrate predators by reducing their food limitation. Accordingly, interactions between invasive species in multiplyinvaded ecosystems can also lead to interactions whereby one invader positively affects the population of the other. Indeed, in extremis, interactions between invasive species can lead to synergetic effects and invasional meltdowns, whereby entire communities are reorganized by cascades of successive invasions (see Simberloff and Von Holle 1999; Simberloff 2006).

Attempting to restore multiply-invaded ecosystems is challenging because the functional roles of species and the structure of the system have been altered (Zavaleta et 
al. 2001; Bull and Courchamp 2009). Indeed, removing one of several established invasive species may result in unpredictable and sometimes undesirable outcomes (Bull and Courchamp 2009; Courchamp et al. 2003). For example, the removal of feral cats Felis catus from Macquarie Island increased the abundance of rabbits Oryctolagus cuniculus leading to substantial local and landscape-scale reduction of native vegetation (Bergstrom et al. 2009). Management failures focused on single invaders and that overlooked the interactions with other invasive species, have led to poor return from investment in some eradication attempts and perpetuated a sense of pessimism about the scope to reverse the tide of invasions (e.g. Roemer et al. 2002; Bergstrom et al. 2009; Kessler 2011). Indeed, managing established invasive species is expensive, estimated at approximately 22 thousand million US \$ annually in the United States alone (Pimentel et al. 2005). Thus current best practice in management planning includes explicit consideration of potential interactions between invasive species (Bull and Courchamp 2009; Veitch et al. 2012; Kuebbing et al. 2013; Simberloff et al. 2013).

One invasive species that is established in multiply-invaded ecosystems and is the focus of much control effort is the American mink Neovison vison (mink hereafter; see Bonesi and Palazon 2007). The species is native to North America (Dunstone 1993) but it is now established as an invasive species in much of Europe, southern South America, China and northern Japan following escapes from fur farms (Jeschke and Strayer 2005; Bonesi and Palazon 2007; see supplementary material Figure S1). It is currently included amongst the worst invasive alien species threatening biodiversity and native wildlife in Europe (Anon 2007) with at least 47 native species badly affected by its generalist feeding behavior concentrated along riparian and coastal corridors (Genovesi et al. 2012). Similar negative effects have been seen in South America (e.g. Schuttler et al. 2008; Ibarra et al 2009). In its invaded range, American mink co-exists 
with established non-native prey species with some evidence of both exploitative and positive interactions. Mink spread in Poland coincided with a collapse in non-native but long established muskrat populations, a favored prey of mink in its native range (Errington 1943). Muskrat reach high densities outside their native range and represent an abundant prey for mink. This combined with a possible loss of anti predator avoidance is thought to have contributed to mink spread in Poland (Brzeziński et al. 2010). The coexistence of mink and naturalized European rabbits in Scotland leads to an apparent predator-mediated pattern of competition between rabbits and native water voles (Oliver et al. 2009). Studies in Catalonia by Melero et al. (2008) point to a potential strong interaction between mink and non-indigenous crayfish species (NICS hereafter), with mink diet dominated by NICS but crayfish populations seemingly unaffected and persisting at high density. Indeed, based on the prevalence of NICS in mink diet in Ireland, Smal (1991) suggested that the availability of crayfish could be a major determinant of mink density.

Here we evaluate the hypothesis that NICS trophically subsidize mink populations outside their native range through reduced food limitation and consequently elevated mink densities in the presence of NICS. In order to assist with prioritization of mink control programs, we also explore to what extent subsidized mink populations are more resilient to lethal control and how control cost would have to be escalated to contend with mink population subsidized by NICS. Using published data, we ask (Q1) whether the prevalence of crayfish in mink diet correlates with crayfish abundance and origin (native or NICS); (Q2) whether this prevalence correlates with mink population carrying capacity by increasing mink density and reducing home range sizes; (Q3) whether mink populations are more resilient to control/eradication with higher carrying capacity; and, if so, (Q4); whether there is also a related increase in terms of financial 
investment and animal welfare cost (number of harvested mink) even in the absence of change in compensation through density dependence.

\section{Materials and methods}

Literature review

To answer Q1 we searched the literature using combinations of keywords related to crayfish abundance, distribution and origin; and mink diet, home range and density. For example, for searching information on mink diet we used "diet" OR "trophic" OR “Feed*” AND "mink" OR "vison". We gathered information from the peer-reviewed and grey literature via Web of Knowledge v5.5 (Thomson Reuters, 2012) and Google Scholar search engine. We also used the inventories of DAISIE (Delivering Alien Invasive Species Inventories for Europe; www.europe-aliens.org), GISIN (Global Invasive Species Information Network, http://www.gisin.org) and the IUCN (http://www.iucn.org/). We matched studies of mink diet with information on mink density, mink home range and crayfish abundance data where possible.

The most commonly used methods to characterize carnivore diet are the relative frequency of occurrence of a particular prey item (total number of occurrences of the item divided by the total number of items found) and the percentage of occurrence in scats. We used the relative frequency of occurrence of crayfish in mink diet (RFO hereafter) for our analyses as it provides more accurate information about the relative contribution of prey items. However, some studies only quoted percentage of occurrence. In these cases, we used the studies with both data on RFO and percentage of occurrence to derive a linear relationship between these and used it to calculate the 
missing values of RFO (see next section and results). Mink, as most mammalian carnivores, have intra-sexual territories such that home range size provides a good estimate of territory size. Due to mink's riparian habits, its home range sizes obtained from radio-telemetry are usually reported as linear kilometers of watercourse used, which is accepted to include the riparian or shore area. Thus we did not use studies that did not report home ranges in this manner (see supplementary material Table S2). Male and female mink are known to have different home range size (e.g. Birks and Linn 1982). Thus, we only used those studies that quoted average home range of males and females separately, and included sex as a factor in order to check for sex differences in the response of home range size to crayfish in mink diet. As with home ranges, mink density is also reported per unit of linear length of waterways (mink/km). Thus we only used average mink density values from studies that expressed it in this way, or allowed density to be calculated in this manner (see supplementary material Table S2). The full data set and its related references are available in the supplementary material Table S1.

Statistical analyses and modeling

\section{Crayfish and its contribution to mink diet}

We first evaluated the relation between RFO and percentage of occurrence in mink diet using a general linear model (GLM) to predict the missing values of RFO. We used a GLM to check for variation in the contribution of crayfish to mink diet (RFO) in relation to crayfish abundance and whether the relationship varied according to whether the crayfish species involved was native or introduced (Q1). Little data is available on crayfish abundances and most of the information was qualitative based on categories of 
abundances (e.g. abundant, common or scarce). We thus used crayfish abundance as a categorical variable. We also considered models including the interaction between crayfish abundance and origin. Finally, we used generalized linear mixed model (GLMM) to test the potential effects of RFO on mink density fitted with identity (Gaussian distribution) and on home range fitted with a log link function (Poisson distribution) (Q2). Alternative models for mink density and home range versus RFO were as follows: for mink density versus RFO, we considered models including season as a factor; in the case of the home range size we considered models with season, sex and their interaction and related three reduced nested models. In addition, we also tested for any relation between home range size and mink density to better understand their correlation and effect on the carrying capacity. In this case we also evaluated a model that included sex as factor. In all models, study location was set as random effect given some studies were conducted at the same location. Model selection was carried out based on AIC. The full list of models and AICs (including $\triangle \mathrm{AIC}$ and AIC weights) are provided in the supplementary material Table S3.

\section{Modeling the effect of crayfish on mink resilience to control}

To determine whether mink populations coexisting with NICS are more resilient to harvesting for eradication (Q3), we used a simple model to compare the effect of simulated harvesting on mink populations with different carrying capacities $(K)$. These $K$ were chosen based on the analyses described above. We contrasted three worst case scenarios, each assuming NICS affect home range size of females, the resource-limited sex, assuming no mating limitations. We used a Ricker model with constant harvesting to explore the effect of fixed harvest in the three different situations $\left(K_{a}, K_{b}, K_{c}\right)$. The
Formatted: Font: No underline, Font color: Auto

Formatted: Font: (Default) Times New Roman, 12 pt, No underline, Font color: Auto, Not Highlight

Formatted: Font: (Default) Times New Roman, 12 pt, No underline, Font color: Auto, Not Highlight

Formatted: No underline, Font color: Auto, Not Highlight 
Ricker model is one of the simplest and most commonly used density-dependent, discrete time single species model

$$
N_{t+1}=\left[\left(N_{t}-H\right) \exp \left[r_{m}\left(1-\frac{\left(N_{t}-H\right)}{K_{j}}\right)\right]\right]-H
$$

where $N_{t}$ and $N_{t+1}$ are mink pre-breeding population densities in years $t$ and $t+1, H$ is a constant off-take, $K_{j}$ is the carrying capacity with $j=a, b, c$; and $r_{m}$ is the maximum rate of increase of the population. In the absence of specific information in the literature on $r_{m}$ for American mink, we used studies on American martens Martes americana, and ferret Mustela putorius furo yielding similar values of 1.0-1.3 year-1 (Fryxell et al. 1999; Barlow and Norbury 2001). We used $r_{m}=1.3$ in keeping with our wish to explore worst case scenarios. $H$ was set as constant, as our aim was to compare the effect of different carrying capacities $(K)$ on residual densities $\left(N_{t}\right)$ when mink populations are harvested. To facilitate comparison between the three assumed equilibrium population densities reflecting different prey resources $\left(K_{j}\right)$, we simulated a river system $100 \mathrm{~km}$ long and assumed identical initial and equilibrium population sizes $N_{0_{j}}=K_{j}$. We then estimated the minimum annual number of harvested mink $\left(H_{\text {effective }}\right)$ at which the compensatory potential of the mink population has been exceeded and the population starts declining towards extinction. Finally, we also estimated the minimum number of harvested mink per year that would lead to eradication in 9 years $\left(H_{\text {time-effective }}\right)$, the mean duration of two LIFE projects (the EU's financial funding for environmental and nature conservation projects, http://ec.europa.eu/environment/life/).

All 3 scenarios considered include a low density phase prior to eradication when a decline in trapping effectiveness is expected. This could be captured in the model by varying $H$. However in the absence of variation in density dependence, and because our 
aim was to compare the effect of different carrying capacities, adding this degree of realism would add no insights. We thus assumed that the per capita removal cost was constant irrespective of residual density as this does not affect comparing the cost of managing mink at different carrying capacities (Q3). Thus for illustrative purposes we considered the per capita cost of dispatching a mink as constant (Q4). With some exceptions (see Bryce et al. 2011), current management projects are based on the use of professional trappers (e.g. Spain, France, Germany and Poland) and, most commonly, mink are dispatched by qualified veterinarians whose service contribute a fixed per mink cost. In Spain we estimated this cost as $60 €$ per mink.

All statistical analyses and modeling were done using R software version 15.0.

\section{Results}

Crayfish and its contribution to mink diet

Twenty-four of 41 studies on mink diet also had information on density and/or home range size. Of these, eight had data on both density and home range sizes, thirteen had data on density but not home range sizes and only three had data on home range but not on density (see supplementary material Table S1). All studies were undertaken in Europe, Chile or Argentina. There were no data from Japan or China.

The contribution of crayfish to mink diet (RFO) was strongly positively related to its percentage of occurrence $\left(r^{2}=0.95 ; F_{1,10}=231.9, P<0.0001\right)$. The formula that best defined their relation, $\mathrm{RFO}=-0.14 \pm 2.58(\mathrm{SE})+(0.77 \pm 0.05 *$ Percentage of occurrence), was used to calculate RFO for those studies that did not report it. The observed RFO of crayfish in mink diet varied between $0-89 \%$. The observed and 
estimated RFO of crayfish in mink diet increased with increasing crayfish abundance $\left(F_{2,34}=69.57, \mathrm{P}<0.0001 ;\right.$ Fig. 1a). Crayfish proportion in mink diet was also higher when crayfish were not native $(\mathrm{F}=7.09, \mathrm{P}=0.012$; Fig. $1 \mathrm{~b})$. The relationship between crayfish abundance and RFO in mink diet was not affected by crayfish origin (native $v s$ invasive, no interaction*RFO not retained in model selection).

Average mink density increased significantly with the contribution of crayfish to mink diet. Populations where crayfish contributed $36.6 \%$ or more to RFO mink diet reached densities higher than 0.9 mink/km (Fig. 2a, Table 1). Mink with higher consumption of crayfish had smaller home ranges. All populations where crayfish had a RFO of $59 \%$ or more in mink diet had home ranges smaller than $1 \mathrm{~km}$. Males had larger home ranges than female mink but the magnitude of this difference was not affected by crayfish RFO (Fig. $2 b$, Table $1 ; \mathrm{P}=0.2$ ) or seasonality (not retained in model selection). Where mink had smaller home range they also reached higher density; but the relationship was loglinear (Fig. 2c, Table 1) with the smallest mink home range $0.45 \mathrm{~km}$ long.

\section{Modeling the effect of crayfish on mink resilience and management}

We used the minimum value of female home range size for the scenario where NICS subsidized the mink population, $0.45 \mathrm{~km}$ yielding to $K_{a}=2.22 \mathrm{mink} / \mathrm{km}$; and the average and maximum values of the known home range of females: $1.79 \mathrm{~km}$ and 2.85 $\mathrm{km}$ respectively, yielding $K_{b}=0.56$ and $K_{c}=0.35 \mathrm{mink} / \mathrm{km}$ respectively. Estimated annual number culled leading to population decline $\left(H_{\text {effective }}\right)$ differed according to the assumed carrying capacity with higher values required for populations with higher carrying capacity: $H_{\text {effective }}=53$ for those populations with the highest $K_{a} ; H_{\text {effective }}=14$ 
for $K_{b}$ and $H_{\text {effective }}=9$ for $K_{c}$. Time to eradication varied with $H_{\text {effective }}$ of each population: 30 years of culling would be required to achieve eradication for the scenario with the highest carrying capacity, $K_{a}$ but less than 11 years for the other two scenarios (Fig. 3). Accordingly, the associated cost to reach each $H_{\text {effective }}$ until eradication increased with the carrying capacities: $95.4 \mathrm{~K} €$ for 1590 mink harvested in 30 years of management in the population with $K_{a} ; 9.2 \mathrm{~K} €$ for 154 mink and 11 years in $K_{b}$; and $4.9 \mathrm{~K} €$ for 81 mink in 9 years in the population with $K_{c}$. Because $H_{\text {effective }}$ overcomes the compensation capacity of a population, increasing the annual culling number by four female mink per year for $K_{a}$ and by one for $K_{b}$ was sufficient to reduce time to extinction to a maximum of 9 years for both. Increasing culling rate, $H_{\text {time-effective }}$ reduced the final cost to $30.8 \mathrm{~K} €$ for 513 mink harvested before eradication in $K_{a}$; and to $8.1 \mathrm{~K} €$ for 135 mink in $K_{b}$ (Fig. 4).

\section{Discussion}

We have provided evidence of a positive effect of crayfish on mink with mink densities correlating positively and home range size negatively with the proportion of crayfish in mink diet respectively. In addition, high mink carrying capacities increased mink population resilience to control, as illustrated by our simple model, and would also increase related management costs should eradication be attempted.

\section{Trophic subsidies amongst invasives}

Most but not all abundant crayfish populations in our analyses were non-native but, irrespective of their indigenous or non-native origin, abundant crayfish populations 
were intensely consumed by mink, being detected in $48-89 \%$ of scats. In such circumstances, mink take up small home ranges and reach higher densities than if their carrying capacity was set at a lower level by food limitation. NICS subsidize mink populations by increasing prey biomass/profitability and reducing food limitation. The elevated densities of mink populations increased their resilience to simulated control (higher $H_{\text {effective }}$ ) and the costs of simulated eradication. The model that led to this insight does of course leave out too much detail of both mink biology and response to harvesting, such as a hypothetical impact of crayfish abundance on the form of density dependence. It also does not provide a quantitative assessment of the level of harvest required to eliminate any real mink population. As such, it should not be used for management planning. Rather, it illustrates how mink population resilience to harvesting increases in the presence of crayfish. Whereas a modest annual harvest of 9 female mink/year/100 km achieves eradication of the model populations with low carrying capacity $\left(K_{c}\right)$, an almost $500 \%$ increase in female mink harvest /year/100km is require to extinguish the population with higher carrying capacity $(K a)$. This results in a threefold increase in time to eradication and an approximately twenty fold increase in the cumulative management cost.

NICS most often achieve higher carrying capacities than native crayfish and are currently widely distributed (Gherardi et al. 2011). Our analyses suggest that those areas already invaded by NICS but not yet reached by mink are more susceptible to its invasion. Once mink are established, our models predict that their eradication will be challenging. Such a scenario is unfolding in northern Portugal, where the red swamp crayfish is an abundant invasive species (Holdich 2002; Holdich et al. 2010) and mink are currently arriving from nearby areas (Rebelo et al. 2012). Another consequence of small home range size in areas where mink coexist with abundant crayfish is the 
production of a larger number of dispersers that are unable to obtain a territory near the natal area, the process implicitly responsible for density dependence in our simulations. Emigration from areas where mink and crayfish coexist could lead to increased mink invasion pressure in surrounding areas, irrespective of their invasion status.

Furthermore, NICS may invade areas following mink and we predict this would result in elevated mink densities. For example, signal crayfish Pacifastacus leniusculus have recently been introduced in northern Scotland (Peay et al. 2006) where mink are long established (National Biodiversity Network 2013) but effectively controlled as part of community led conservation efforts (Bryce et al. 2011). While the signal crayfish are restricted to a handful of localized populations at present, maintaining northern Scotland free of breeding mink would become much more challenging should crayfish be allowed to spread.

\section{Management implications}

Depressing crayfish density to manage mink could be an option for managing mink; however, this is not currently practically achievable. Controlling invasive crayfish is exceptionally challenging as they spread fast and have enormous compensatory capacity, such that they appear inexpugnable when established (Gherardi et al. 2011). Indeed, to our knowledge no effective long-term eradication has been achieved and containment attempts through the erection of barriers to dispersal are inevitably shortterm and local solutions. Should it become feasible to eradicate NICS over meaningful scales, this should be accompanied by efforts to mitigate the risk of a short term increase in mink predation on native prey items that might be expected owing to mink generalist predatory behavior. 
To conclude, given that funding constrains management actions, restoration

attempts should focus on areas where invasive crayfish are not abundant and they should be prioritized for mink control since for the moment mink can be removed with reasonable investment, unlike invasive crayfish species. When the management aim is to prevent mink from spreading further, proximity to areas where mink coexist with abundant crayfish should be considered as a factor that will increase the risk of mink invasion. Indeed mink emigration rates from areas invaded by NCIS is predicted to be high. Furthermore, leaving incipient crayfish invasions un-managed, as is presently the case in northern Scotland, risks making mink control impractical over large surrounding areas in the future. Lastly, we illustrated how the ecological context of attempts to control invasive species will affect their likely success and cost. Thus it would be unwise to use costs of eradicating mink populations preying on native prey only to estimate the eradication costs for populations subsidized by non native crayfish. Simplistic as it is, our model reinforces the value of ecological understanding in informing management practice.

\section{Acknowledgments}

YM was funded by the Postdoctoral Individual Fellowship Beatriu de Pinós \#2010-BPA-00453 (AGAUR) and the Marie Curie Actions Individual Fellowship \#275217 (FP7PEOPLE-201-IEF Marie Curie Actions). XL was supported in part by a Leverhulme Trust Research Fellowship. We thank Rupert Houghton and two reviewers for helpful comments.

\section{References}

Anon (2007) Europe's environment. The fourth assessment. Copenhagen

Barlow N, Norbury G (2001) A simple model for ferret population dynamics and control in semi-arid New Zealand habitats. Wildlife Res 28:87-94. doi:10.1071/WR99090 
Bergstrom DM, Lucieer A, Kiefer K, Wasley J, Belbin L, Pedersen TK, Chown SL (2009) Indirect effects of invasive species removal devastate World Heritage Island. J Appl Ecol 46:73-81. doi:10.1111/j.1365-2664.2008.01601.x

Birks JDS, Linn IJ (1982) Studies of home range of the feral mink, Mustela vison. Sym Zool Soc Lond 49:231-257

Bonesi L, Palazón S (2007) The American mink in Europe: Status, impacts, and control. Biol Conserv 134:470-483. doi:10.1016/j.biocon.2006.09.006

Bruno JF, Stachowicz JJ, Bertness MD (2003) Inclusion of facilitation into ecological theory. TREE 18:119-125. doi:10.1016/S0169-5347(02)00045-9

Bryce R, Oliver MK, Davies L, Gray H, Urquhart J, Lambin X (2011) Turning back the tide of American mink invasion at an unprecedented scale through community participation and adaptive management. Biol Conserv 144:575-583. doi:10.1016/j.biocon.2010.10.013

Brzeziński M, Romanowski J, Żmihorski M, Karpowicz K (2010) Muskrat (Ondatra zibethicus) decline after the expansion of American mink (Neovison vison) in Poland. Eur J Wildlife Res 56:341-348. doi:10.1007/s10344-009-0325-9

Bull LS, Courchamp F (2009) Management of Interacting Invasives: Ecosystem Approaches. In: Clout MN, Williams PA (eds) Invasive Species Management. A Handbook of Principles and Techniques. Oxford University Press, Oxford, pp 232248

Bulleri F, Bruno JF, Benedetti-Cecchi L (2008) Beyond competition: incorporating positive interactions between species to predict ecosystem invasibility. PLoS Biol 6:e162. doi:10.1371/journal.pbio.0060162

Courchamp F, Woodroffe R, Roemer G (2003) Removing protected populations to save endangered species. Science 302:1532. doi:10.1126/science.1089492

Dunstone N (1993) The Mink. T and A D Poyserd Ltd, London

Elton CS (1958) The Ecology of Invasions by Animals and Plants (CS Elton, Ed.). Methuen, London

Errington PL (1943) An analysis of mink predation upon muskrats in north-central United States. Iowa Agricultural Experiment Station Research Bulletin 24:377-393

Fargione JE, Tilman D (2005) Diversity decreases invasion via both sampling and complementarity effects. Ecol Lett 8:604-611. doi:10.1111/j.14610248.2005.00753.x

Fridley JD, Stachowicz JJ, Naeem S, Sax DF, Seabloom EW, Smith MD, Stohlgren TJ, Tilman D, Holle B Von (2007) The invasion paradox: reconciling pattern and process in species invasions. Ecol 88:3-17 
Fryxell JM, Falls JB, Falls EA, Brooks RJ, Dix L, Strickland MA (1999) Density dependence, prey dependence, and population dynmics of martens in Ontario. Ecol 80:1311-1321

Genovesi P, Carnevali L, Alonzi A, Scalera R (2012) Alien mammals in Europe: updated numbers and trends, and assessment of the effects on biodiversity. Integr Zool 7:247-253. doi:10.1111/j.1749-4877.2012.00309.x

Gherardi F, Aquiloni L, Diéguez-Uribeondo J, Tricarico E (2011) Managing invasive crayfish: is there a hope? Aquatic Sciences - Research Across Boundaries 73:185200. doi:10.1007/s00027-011-0181-z

Holdich DM, Reynolds JD, Souty-Grosset C, Sibley PJ (2010) A review of the ever increasing threat to European crayfish from non-indigenous crayfish species. Bulletin Français de la Pêche et de la Pisciculture 394-395:46. doi:10.1051/kmae/2009025

Holdich DMM (2002) Distribution of Crayfish in Europe and Some Adjoining Countries. Bulletin Français de la Pêche et de la Pisciculture 367:611-650. doi:10.1051/kmae:2002055

Ibarra JT, Fasola L, Macdonald DW, Rozzi R, Bonacic C (2009) Invasive American mink Mustela vison in wetlands of the Cape Horn Biosphere Reserve, southern Chile: what are they eating? Oryx 43:87. doi:10.1017/S0030605308099997

Jeschke JM, Strayer DL (2005) Invasion success of vertebrates in Europe and North America. P Natl Acad Sci USA 102:7198-7202. doi:10.1073/pnas.0501271102

Kessler C (2011) Invasive species removal and ecosystem recovery in the Mariana Islands; challenges and outcomes on Sarigan and Anatahan. In: Veitch CR, Clout MN, Towns DR (eds) Island invasives: eradication and management. Proceedings of the International Conference on Island Invasives. IUCN, Gland, Switzerland, pp 320-324

Kuebbing SE, Nuñez MA, Simberloff D (2013) Current mismatch between research and conservation efforts: The need to study co-occurring invasive plant species. Biol Conserv 160:121-129

Lenz TI, Facelli JM (2003) Shade facilitates an invasive stem succulent in a chenopod shrubland in South Australia. Austral Ecol 28:480-490

Lonsdale WM (1999) Global patterns of plant invasions and the concept of invasibility. Ecol 80:1522-1536. doi:10.1007/BF01238186

Mack R, Simberloff D, Lonsdale WM, Evans H, Clout M, Bazzaz FA (2000) Biotic invasions: causes, epidemiology, global consequences, and control. Ecol Appl 10:689-710 
Melero Y, Palazón S, Bonesi L, Gosàlbez J (2008) Feeding habits of three sympatric mammals in NE Spain: the American mink, the spotted genet, and the Eurasian otter. Acta Theriol 53:263-273. doi:10.1007/bf03193123

National Biodiversity Network (2013) Grid map of records on the Gateway for American Mink (Neovison vison).

Oliver M, Luque-Larena JJ, Lambin X (2009) Do rabbits eat voles? Apparent competition, habitat heterogeneity and large-scale coexistence under mink predation. Ecol Lett 12:1201-1209. doi:10.1111/j.1461-0248.2009.01375.x

Peay S, Hiley PD, Collen P, Martin I (2006) Biocide trial to eradicate signal crayfish in the North Esk catchment. Bulletin Français de la Pêche et de la Pisciculture 380:1363-1379. doi:10.1051/kmae:2006041

Pimentel D, Zuniga R, Morrison D (2005) Update on the environmental and economic costs associated with alien-invasive species in the United States. Ecol Econ 52:273-288. doi:10.1016/j.ecolecon.2004.10.002

Rebelo R, Rodrigues DC, Simoes L, Mullins J, Mendes R, Lampa S, Moreira F, Fernandes C, Santos SM (2012) The invasion of northwestern Portugal by the American mink (Neovison vison): rate of spread and diet. In: Invasive Species Workshop. Invasive Species- threat and management. Bialowieza, Poland

Relyea RA (2003) How prey respond to combined predators: a review and an empirical test. Ecol 84:1827-1839. doi:10.1890/00129658(2003)084[1827:HPRTCP]2.0.CO;2

Rodriguez-Cabal M a., Barrios-Garcia MN, Nunez M a. (2012) Positive interactions in ecology: filling the fundamental niche. Ideas in Ecol n Evol 5:36-41. doi:10.4033/iee.2012.5.9.c

Roemer GW, Donlan CJ, Courchamp F (2002) Golden eagles, feral pigs, and insular carnivores: how exotic species turn native predators into prey. P Natl Acad Sci USA 99:791-6. doi:10.1073/pnas.012422499

Schuttler E, Carcamo J, Rozzi R (2008) Diet of the American mink Mustela vison and its potential impact on the native fauna of Navarino Island, Cape Horn Biosphere Reserve, Chile. Revista Chilena de Historia Natural 81:585-598

Simberloff D (1996) Impacts of Introduced Species in the United States. Consequences 2

Simberloff D (2006) Invasional meltdown 6 years later: important phenomenon, unfortunate metaphor, or both? Ecol Lett 9:912-919. doi:10.1111/j.14610248.2006.00939.x

Simberloff D, Von Holle B (1999) Positive Interactions of Nonindigenous Species: Invasional Meltdown? Biol Invasions 1:21-32. doi:10.1023/a:1010086329619 
Simberloff D, Martin J-L, Genovesi P, Maris V, Wardle DA, Aronson J, Courchamp F, Galil B, García-Berthou E, Pascal M, Pyšek P, Sousa R, Tabacchi E, Vilà M (2013) Impacts of biological invasions: what's what and the way forward. TREE 28:58-66

Smal CM (1991) Population studies on feral American mink Mustela vison in Ireland. J Zool 224:233-249. doi:10.1111/j.1469-7998.1991.tb04802.x

Stachowicz JJ, Whitlatch RB, Osman RW (1999) Species Diversity and Invasion Resistance in a Marine Ecosystem. Science 286:1577-1579

Tablado Z, Tella JL, Sanchez-Zapata JA, Hiraldo F (2010) The Paradox of the LongTerm Positive Effects of a North American Crayfish on a European Community of Predators. Conserv Biol 24:1230. doi:10.1111/j.1523-1739.2010.01483.x

Tilman D (1997) Community, invasibility, recruitment limitation, and grassland biodiversity. Ecol 78:81-92. doi:10.1890/00129658(1997)078[0081:CIRLAG]2.0.CO;2

United-Nations (1996) Earth Summit. Rio Convention 1992.

Veitch CR, Clout MN, Towns DR (2012) Island invasives: eradication and management: proceedings of the International Conference on Island Invasives (CR Veitch, MN Clout, and DR Towns, Eds.). IUCN, Gland, Switzerland

Vitousek PM, D’Antonio CM, Loope LL, Westbrooks R (1996) Biological invasions as global environmental change. Am Sci 84:468-478

Zavaleta ES, Hobbs RJ, Mooney H a. (2001) Viewing invasive species removal in a whole-ecosystem context. TREE 16:454-459. doi:10.1016/S0169-5347(01)021942 
Table 1 Results for the best GLMM models on the effects of the relative frequency of occurrence (RFO) of crayfish in mink diet on mink density (mink/km) and home range size $(\mathrm{km})$, and between home range size and mink density. Data was gathered by means of literature review on mink diet, home range and density (see supplementary material Table S1). In all cases, location of each study was set as random effect to account for several studies taken place at some location and control its effect on the variance of the response variable (see supplementary material Table $\mathrm{S} 1$ for the list of locations). NICS stands for non-indigenous crayfish species. Model selection was done based on AIC (see supplementary material Table S3).

\begin{tabular}{lllll}
\hline Response variable & Factor & Estimate & SE & P-value \\
& & & & (Ho Estimate $=0)$ \\
\hline Mink density & Intercept & 0.33 & 0.09 & 0.006 \\
& Log(RFO) & 0.19 & 0.04 & 0.013 \\
& Log(RFO) & -0.35 & 0.10 & 0.009 \\
& Sex Female & 1.09 & 0.23 & 0.002 \\
& Sex Male & 1.65 & 0.14 & 0.005 \\
& Log(Home range) & -0.35 & 0.10 & 0.018 \\
& Sex Female & 0.86 & 0.09 & $<0.0001$ \\
& Sex Male & 1.04 & 0.09 & 0.11 \\
\hline
\end{tabular}


Fig. 1 Contribution of crayfish to American mink Neovion vison diet expressed as relative frequency of occurrence (RFO) and in relation to (a) crayfish abundance: abundant $(n=12)$, common $(n=8)$ or scarce $(n=19)$; and (b) crayfish origin: NICS ( $=14)$ or native $(\mathrm{n}=25)$. RFO $v s$ crayfish abundance: $\mathrm{F}_{2,34}=69.57, \mathrm{P}<0.0001$; and RFO vs crayfish origin: $\mathrm{F}_{1,35}=7.09, \mathrm{P}=0.012$. Location of each study was set as random effect ( $n=30$ and $n=29$ respectively). Boxes represent the data contained between the lower and upper quartile, inside the solid black lines indicates the median, dashed lines indicate minimum and maximum values, circles indicate outliers

Fig. 2 Log linear relationships of (a) mink density (mink/km); and (b) mink home range size $(\mathrm{km})$ in relation to contribution of crayfish to mink diet expressed as RFO; and (c) mink density $(\mathrm{mink} / \mathrm{km})$ in relation to mink home range $(\mathrm{km})$. Grey stands for female, black for male in (b) and (c). Continuous line relates to best model fit, dashed lines relate to the $95 \%$ confident intervals

Fig. 3 Change in mink population size $(\mathrm{N})$ trough time (year) modelled in the three populations with different carrying capacity and no natural changes: (a) $K_{a}=2.22$, (b) $K_{b}=0.56$ and (c) $K_{c}=0.35 \mathrm{mink} / \mathrm{km}$; and with a set of different number of mink captures per year $(H)$ including the minimum $H$ that leads to eradication $\left(H_{\text {effective }}\right)$ and the minimum number of harvested mink per year that would lead to eradication in 9 years $\left(H_{\text {time-effective }}\right)$

Fig. 4 Cumulative cost in thousands of Euros and cumulative number of harvested mink for the $H_{\text {effective }}$ and $H_{\text {time-effective }}$ of the three mink populations modeled with different carrying capacities, $K_{a}=2.22, K_{b}=0.56$ and $K_{c}=0.35 \mathrm{mink} / \mathrm{km}$. The dot at the end of the lines indicates eradication has been achieved 


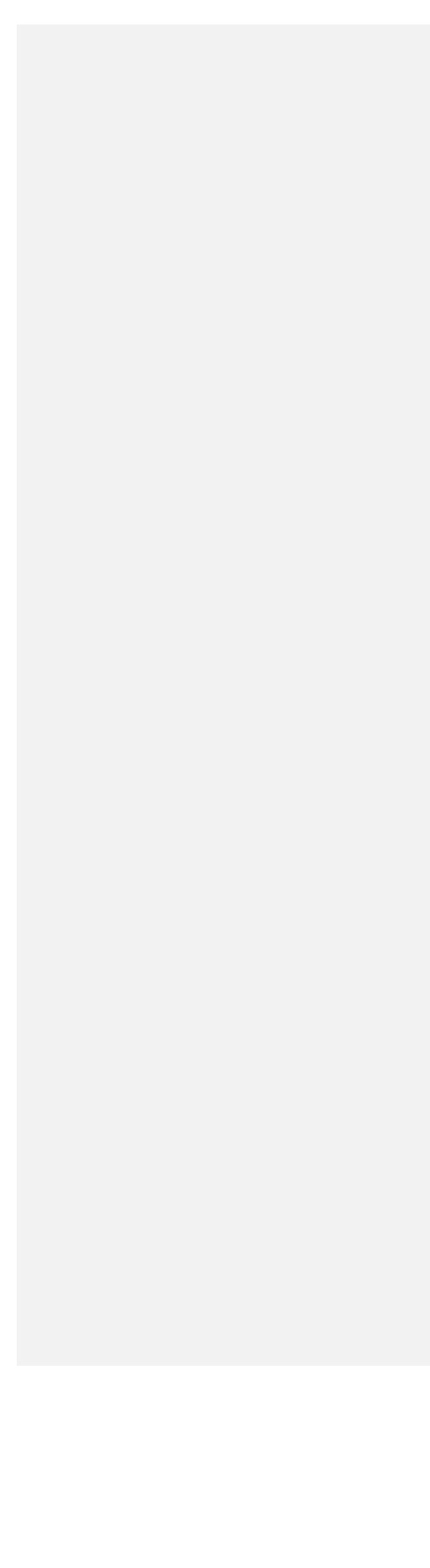

